\title{
Anti-Wrinkling Effect of Noni (Morinda citrifolia) by Antioxidant and Anti-Inflammatory Properties
}

\author{
Soo-Cheol Choi ${ }^{1}$ and Young Han Youn ${ }^{2 *}$ \\ ${ }^{1}$ Doctoral student, Department of Chemistry, Kunsan National University, Kunsan 54150, Korea \\ ${ }^{2}$ Professor, Department of Beauty Care, Sohae College, Kunsan 54116, Korea
}

\section{ABSTRACT}

Noni has been used for medicinal purposes for more than 2,000 years in South Pacific Polynesia, China and India, and has been heavily ingested as an extract for its excellent antioxidant and anti-inflammatory effects. However, a recent study found that the noni extract causes digestive disorders, kidney problems, and liver diseases, which made it necessary to use it for other purposes than as an extract. In this study, we want to evaluate the potential of noni as an anti-oxidant, anti-inflammatory and anti-wrinkling agent. Methods: Noni was freeze-dried, extracted in water, and concentrated. Skin cells were treated with the noni extract for $24 \mathrm{hrs}$ and then were exposed to UVB $\left(55 \mathrm{~mJ} / \mathrm{cm}^{2}\right)$. After $48 \mathrm{hrs}$ of incubation, pro-inflammatory cytokine, elastase, MMP-1 and type-1 procollagen levels were measured by ELISA. Results: To find out the antioxidant effect of the noni extract, the DPPH and ABTS radical scavenging activity experiments were conducted and the noni extract showed $97.0 \%$ and $92.0 \%$ antioxidant efficacy at $200 \mu \mathrm{g} / \mathrm{mL}$ respectively. The noni extract (50 and $100 \mu \mathrm{g} / \mathrm{mL}$ ) decreased IL-6 and TNF- $\alpha$ in RAW 264.7 cells induced by LPS in a concentration-dependent manner. In the RT-PCR experiment involving NO production, the noni extract (50 and $100 \mathrm{\mu g} / \mathrm{mL}$ ) inhibited NO production by strongly inhibiting iNOS mRNA expression, and also inhibited the elevation of MMP-1 and elastases caused by UVB irradiation by $25.0 \%$ and $7.0 \%$ respectively. In addition, type-1 procollagen was elevated by $20.0 \%$ by the noni extract treatment in HaCaT cells. Conclusion: The noni extract has photoprotective ability by reducing proinflammatory mediators, elastase and MMP-1 production, and elevation of collagen synthesis. Our findings suggest that the noni extract might be a good natural substance to protect against UVB-induced premature skin aging.

Keywords: anti-aging, collagen, human Keratinocytes, matrix metalloproteinases, oxidative stress

\section{Introduction}

A wrinkle can be expressed as the twisting of the skin or the deformation of the epidermis and dermis caused by aging. As people age, the epidermis and subcutaneous fat layers start to get thinner, and the rete ridges of the epidermis-dermis boundary become flattened and make the skin weak. The density of skin tissues is reduced and it becomes difficult to deliver nutrition to skin tissues, which is known to sag the skin and make wrinkles (Kim et al., 2010; Kim et al., 2016; Liu et al., 2020; Ye et al., 2016). The aging of the skin involves internal and external factors, and active oxygen species generated by the aging of the skin stimulate the horny layer of the epidermis and dermal fibroblasts, and activate the transcription factor of activator protein-1 (AP-1) and NF- $x$ B (Nuclear factor kappa-light-chain-enhancer of activated $\mathrm{B}$ cells). This makes inflammatory cytokines be secreted in the skin and increases the expression of collagenases (Matrix metalloproteinases, MMPs), which lowers the elasticity of the dermis and causes skin sagging and wrinkles (Kim et al., 2016; Kim et al., 2019; Lee et al., 2014). The elasticity of the skin involves connective tissue proteins that exist in the dermis including collagen and elastin, and anti-wrin-

Received: February 14, 2020, Revised: March 2, 2020, Accepted: March 6, 2020

First author: Soo-Cheol Choi, csc2714@hanmail.net, (1D) https://orcid.org/0000-0003-3026-1423

*Corresponding author: Young Han Youn, younhan0716@hanmail.net, (D) https://orcid.org/0000-0001-5904-3185 
kling agents are composed of substances and ingredients that accelerate the synthesis and suppress the decomposition of the two types of proteins (Youn et al., 2012). In particular, suppressing the activity of matrix metalloproteinases (MMPs), the enzymes involved in the decomposition of collagen and elastin, is used as a criterion for assessing the efficacy of anti-wrinkling cosmetics (Jung et al., 2018; Lee et al., 2018), and for this reason, vitamin A derivatives and adenosine are notified by the Ministry of Food and Drug Safety as an anti-wrinkling agent (Kim et al., 2015; Lee et al., 2013). Schisandra chinensis fruit extract, vitamin $\mathrm{E}$ and ubiquinone are also known to have anti-wrinkling effects (Ahn et al., 2011; Kim et al., 2009).

Noni (Morinda citrifolia) that Polynesians started to use as a food and a folk remedy 2,000 years ago is prevalent in Hawaii and Tahiti and is mainly distributed in volcanic islands in the South Pacific (Kim and Jang, 2016; Choi et al., 2005). The antioxidant effect of Noni is known to be 1.4 times higher than vitamin $\mathrm{C}$ and 1.1 times higher than grape seed powder (Almeida-Souza et al., 2018; Lee et al., 2006; Liu et al., 2018). The fruits of noni are effective against oxidation, bacteria, virus, cancer, flu, allergy and inflammation, boost immunity, and are used as a nutritional supplement to protect the skin, prevent aging, recover health from stress (Hwang et al., 2019; De La Cruz-Sánchez et al., 2019). This study measured the anti-wrinkling and anti-inflammatory effects of the noni extract in skin cells and immunocytes, identified the anti-aging and anti-wrinkling efficacy of the noni extract, and predicted its applicability as a substance for cosmetics.

\section{Research Methods}

\section{Sample preparation}

Noni fruits used as a substance to obtain the noni extract were purchased from an importer who imported noni fruits from New Zealand, and their extract was obtained with water and was used for the following experiments. New Zealand noni fruits were frozen at $-80{ }^{\circ} \mathrm{C}$ for a day and were freeze-dried to obtain fine noni powder. The noni powder was extracted with water at $40{ }^{\circ} \mathrm{C}$ for 24 hours as follows. The extract was centrifuged and filtered to obtain the pure noni liquid extract only. The pre-treated pure noni extract was frozen in a freezer at $-80{ }^{\circ} \mathrm{C}$ for a day and was freeze-dried to obtain a noni liquid extract sample in the form of fine powder. The obtained sample was used in the following experiments.

\section{DPPH free radical scavenging activity}

A 2,2-Diphenyl-1-picrylhydrazyl (DPPH) radical scavenger was measured using the modified version of the method suggested by Blois (1958). The noni extract was diluted with $70 \%$ ethanol to the concentration of 6.25 , 12.5, 25, 50, 100, 200 and $400 \mathrm{mg} / \mathrm{mL}$. DPPH (Sigma-Aldrich Co, USA) was diluted with $70 \%$ ethanol to the concentration of $0.04 \mathrm{mM}$, and was mixed with $100 \mu \mathrm{L}$ of the sample. The mixed solution was reacted at room temperature in a dark room for 20 minutes. After reaction, its absorbance was measured at $492 \mathrm{~nm}$ using a microplate reader (Thermo Fisher Scientific, Rockford, IL, USA). Ascorbic acid, one of the widely-used antioxidants, was used as the positive control group.

\section{ABTS assay}

In this study, 2,2'-azino-bis (3-ethylbenzothiazoline6-sulphonic acid) (ABTS) radical cation decolorization was measured using the modified version of the method suggested by Re et al. (1999), and $7 \mathrm{mM} \mathrm{ABTS}$ and 2.45 $\mathrm{mM}$ potassium persulfate were mixed at the ratio of 1:1 to generate ABTS radicals by melting them in water respectively. To minimize loss of radicals caused by light, it was stored in a dark room for 12 hours. The noni extract was diluted with methanol solution to the concentration of $6.25,12.5,25,50,100,200$ and $400 \mathrm{mg} / \mathrm{mL}$, and the ABTS solution was adjusted to ensure its UV absorbance become 1.00. The solution was added with $20 \mu \mathrm{L}$ of the sample and $180 \mu \mathrm{L}$ of the ABTS solution of a different concentration, and its absorbance was measured at $734 \mathrm{~nm}$ after 10 minutes [5]. Here, ascorbic acid was used as the positive control group. 


\section{Cell culture}

The macrophage cell lines of a mouse (RAW 264.7 cells) and the human dermal fibroblasts cell lines (HaCaT cells) used in this study were purchased from the Korean Cell Line Bank (KCLB, Seoul, Korea). They were cultured under the conditions of $37^{\circ} \mathrm{C}$ and $5 \% \mathrm{CO}_{2}$ using Dulbecco's Modified Eagle's Medium (DMEM; Gibco BRL, Grand Island, NY, USA) added with $10 \%$ fetal bovine serum (FBS; Gibco BRL, Grad Island, NY, USA).

\section{Cell viability (\%)}

$\mathrm{HaCaT}$ cells, the human dermal fibroblasts cell lines used in this study, were dispensed into a 24-well plate at the concentration of $1 \times 10^{5}$ cells/well, and were cultured for 24 hours after treating them with the noni extract of $6.25,12.5,25,50,100,200$ and $400 \mu \mathrm{g} / \mathrm{mL}$ respectively to examine the cytotoxicity of the extract. As the positive control group, TGF- $\beta 1$ was used to measure the viability of cells. To observe the overall distribution of cells that survived in each well, the wells were dyed with crystal violet. First, media were removed from each well and the wells were cleaned with $1 \mathrm{xPBS} 1 \mathrm{~mL} 3$ times. To each well, $200 \mu \mathrm{L}$ of $10 \%$ formalin was added and fixed for 10 minutes. After that, violet $200 \mu \mathrm{L}$ of $1 \%$ crystal made using $20 \%$ methanol was dispensed into each well, and the wells were dyed for 10 minutes at room temperature. After dyeing, the dye solution was removed from each well, and the wells were cleaned with distilled water 6 times. To each well, $250 \mu \mathrm{L}$ of $33 \%$ glacial acetic acid was dispensed, and the solution was diluted 20 times. The diluted solution was transferred to a 96-well plate, and the absorbance of cells was measured at $595 \mathrm{~nm}$ using a microreader (Young et al., 2004).

\section{Measurement of NO (Nitric oxide) production}

The concentration of NO in the culture media was determined through the Griess reaction (Kim et al., 2015). To examine the inhibitory capability of the noni extract against NO, inflammation-induced RAW 264.7 macrophage cells with LPS were added with $400 \mu \mathrm{g} / \mathrm{mL}$ of the extract of $6.25,12.5,25,50,100,200$ and $400 \mu \mathrm{g} / \mathrm{mL}$ and were cultured for 24 hours. After that, to measure the produced amount of NO, the supernatant of the cell-cultured solution was centrifuged at 2,000 rpm and $4{ }^{\circ} \mathrm{C}$ for 10 minutes, and the concentration of $\mathrm{NO}$ was quantified using a nitric oxide kit (Koma Bio Inc.) following the instructions of the manufacturer. The absorbance of the final NO product was measured at $550 \mathrm{~nm}$ using a microplate reader. The produced amount of NO was calculated by comparing it with the standard curve of $\mathrm{NaNO}_{3}$.

\section{In vitro cytokine generation and quantification}

To quantify TNF- $\alpha$ and IL-6, the mouse macrophage cell lines (RAW 264.7 cells) were dispensed into a 24-well plate at $1 \times 10^{6}$ cells/well, and were cultured for 24 hours. The cultured cells were transferred to a culture medium that contains $1 \mu \mathrm{g} / \mathrm{mL}$ of LPS to induce the generation of inflammatory-cytokines (TNF- $\alpha$, IL-6), and were added with the Morinda citrifolia extract of 6.25, 12.5, 25, 50, 100,200 and $400 \mu \mathrm{g} / \mathrm{mL}$ and were cultured for 24 hours. After cultivation, the culture media were centrifuged at 12,000 rpm for 3 minutes to obtain their supernatant, and the cytokines were quantified using an ELISA kit (YOUNG IN, Inc., Korea).

\section{Total RNA extraction}

The total RNA was extracted from inflammation-induced RAW 264.7 cells with LPS using TRIZol (Sigma-Aldrich Co., USA) following the instructions of the manufacturer. The extracted RNA was dissolved in DEPC (Diethyl Pyrocarbonate) water, and reverse transcription polymerase chain reaction (RT-PCR) was performed on the extracted RNA.

\section{Reverse Transcription Polymerase Chain Reaction (RT-PCR)}

To perform polymerase chain reaction (PCR), cDNA was synthesized from mRNA using a RT-PCR kit (Bioneer, Korea) that contains PCR DNA polymerase, buffer, dNTP and tracking dye, and the PCR was performed using a different primer for each gene such as TLR4, MyD88, NF- $x$ B PP65 and NF- $\varkappa$ B P65 for 30 seconds at $94{ }^{\circ} \mathrm{C}$, for 
Table 1. Sequences of target gene-specific primers used in the RT-PCR

\begin{tabular}{ccc}
\hline Target gene & & Sequences \\
\hline \multirow{2}{*}{ iNOS } & Forward & 5'-CCC TTC CGA AGT TTC TGG CAG CAG C-3' \\
& Reverse & $5^{\prime}$-GGC TGT CAG AGC CTC GTG GCT TTG G-3' \\
\multirow{2}{*}{ GAPDH } & Forward & $5^{\prime}$-TGA AGG TCG GTG TGA ACG GAT TTC GC-3' \\
& Reverse & $5^{\prime}$-CAT GTA GGC CAT GAG GTC CAC CAC-3' \\
\hline
\end{tabular}

30 seconds at $55 \sim 62{ }^{\circ} \mathrm{C}$, and for 1 minute at $72{ }^{\circ} \mathrm{C}$, at a total of 35 cycles. Electrophoresis was performed on the PCR products on $1.5 \%$ agarose gel, and was monitored using a UV transilluminator. To quantitative comparison, they were standardized with Glyceraldehyde 3-phosphate dehydrogenase (GAPDH). The sequences of each primer used in this analysis were as shown in Table 1.

\section{Elastase activity inhibitory assay}

To examine the effects of the extract on the skin and wrinkles, N-succinyl-(L-Ala)3-p-nitroanilide was used as a substrate, and the generated amount of p-nitroanilide was measured at $37{ }^{\circ} \mathrm{C}$ for 30 minutes. After that, the inhibitory activity of porcine pancreas elastases was measured. Each testing solution was prepared to become a certain concentration, and $0.1 \mathrm{~mL}$ of each solution was taken into a test tube. Each test tube was added with $0.05 \mathrm{~mL}$ of elastase, pancreatic solution (Type 1 : From Porcine Pancreas, 0.6 Units/mL) dissolved in a $50 \mathrm{mM}$ tris- $\mathrm{HCl}$ buffer $(\mathrm{pH} \mathrm{8.6)}$, and was added with $0.1 \mathrm{~mL}$ of N-succinyl-(L-Ala)3-p-nitroanilide $(1 \mathrm{mg} / \mathrm{mL})$ dissolved in a $50 \mathrm{mM}$ tris- $\mathrm{HCl}$ buffer $(\mathrm{pH} 8.6)$ as a substrate. The test tubes were reacted for 30 minutes, and their absorbance was measured at $410 \mathrm{~nm}$ using a microplate reader.

\section{Measurement of synthesized Type I collagen}

$\mathrm{HaCaT}$ cells were dispensed into wells at the concentration of $1 \times 10^{5}$ cells/well, and were pre-cultured for 24 hours. After being treated with samples, the cells were cultured for 24 hours. The culture media were centrifuged at $800 \mathrm{rpm}$ for 5 minutes, and the content of Type I collagen was measured using a procollagen Type I C-peptide (PIP) EIA kit (TAKARA, Japan).

\section{Measurement of produced matrix metalloproteinase-1 (MMP-1)}

HaCaT cells were dispensed into wells at the concentration of $1 \times 105$ cells/well, and were pre-cultured for 24 hours. After being treated with samples and TNF-alpha simultaneously, the cells were cultured for 24 hours. The culture media were centrifuged at $800 \mathrm{rpm}$ for 5 minutes, add the content of MMP-1 was measured using a human pro-MMP-1 Quantikine ELISA kit (YOUNG IN, Inc., Korea) as percentage to the control group.

\section{Statistical analysis}

Each test analysis was repeated over five times, and analysis of variance (ANOVA) was conducted on the collected data for statistical analysis using the SAS program. Duncan's multiple range test was also conducted to verify significant differences between samples.

\section{Results and Discussion}

\section{Antioxidant activity of noni extract}

To analyze the free-radical scavenging activity of the noni extract, the content of DPPH and ABTS radical was analyzed (Table 2). In the DPPH radical scavenging activity test, the scavenging activity of the noni extract was $92.0 \%$ at $100 \mu \mathrm{g} / \mathrm{mL}$, which indicates that its antioxidant activity was higher than L-ascorbic acid, the positive control group. In the ABTS radical scavenging activity test, the scavenging activity of the noni extract was $89.0 \%$ at $100 \mu \mathrm{g} / \mathrm{mL}$, similar to that in the DPPH radical test. Compared to the positive control group, L-ascorbic acid, the noni extract showed a higher antioxidant activity. 
Table 2. DPPH and ABTS radical scavenging activity of noni extracts $(n=5)$

\begin{tabular}{|c|c|c|c|c|}
\hline \multirow{2}{*}{$\begin{array}{c}\text { Extract conc. } \\
(\mu \mathrm{g} / \mathrm{mL})\end{array}$} & \multicolumn{2}{|c|}{ DPPH scavenging activity (\%) } & \multicolumn{2}{|c|}{ ABTS scavenging activity (\%) } \\
\hline & Noni extract & L-ascorbic acid & Noni extract & L-ascorbic acid \\
\hline 0 & $0.0 \pm 0.0$ & $0.0 \pm 0.0$ & $0.0 \pm 0.0$ & $0.0 \pm 0.0$ \\
\hline 10 & $72.0 \pm 2.0 \mathrm{a}^{\mathrm{z}}$ & $52.0 \pm 1.5 b^{\mathrm{z}}$ & $58.0 \pm 0.8 \mathrm{a}$ & $38.0 \pm 1.2 b$ \\
\hline 50 & $89.0 \pm 1.5 \mathrm{a}$ & $68.0 \pm 2.5 b$ & $72.0 \pm 1.5 \mathrm{a}$ & $57.0 \pm 0.5 b$ \\
\hline 100 & $92.0 \pm 0.8 \mathrm{a}$ & $82.0 \pm 1.3 b$ & $89.0 \pm 1.1 \mathrm{a}$ & $79.0 \pm 1.2 b$ \\
\hline 200 & $97.0 \pm 1.6 \mathrm{a}$ & $83.0 \pm 1.5 b$ & $92.0 \pm 0.6 \mathrm{a}$ & $80.0 \pm 0.8 b$ \\
\hline
\end{tabular}

${ }^{\mathrm{z}}$ Means with the different letters are significantly different $(p<.05)$ by Duncan's multiple range test.

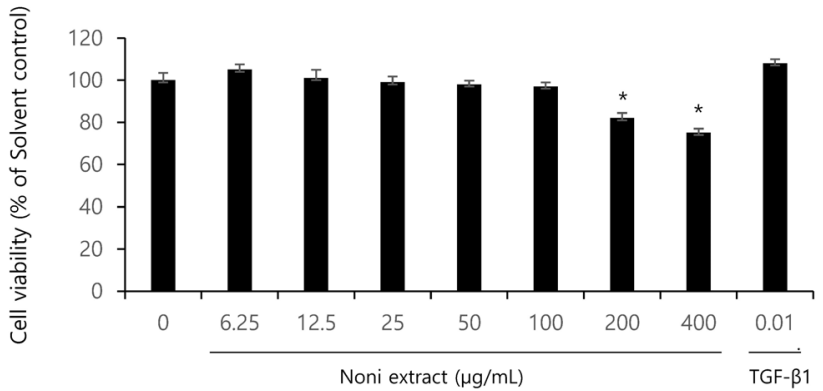

Fig. 1. Effect of noni extract on HaCaT cell viability. The asterisks $(*)$ indicate significant differences from the untreated group $(* \not<.05)$. Error bars indicate standard deviation $(n=5)$.

\section{Cell viability (\%)}

Prior to identifying the anti-inflammatory and anti-wrinkling effects of the noni extract, its cytotoxicity against human fibroblasts (HaCaT cells) that compose the human skin, and the effective dose for a solvent were tested using a crystal violet assay. After $\mathrm{HaCaT}$ cells were treated with the samples diluted at different concentrations $(6.25,12.5$, $25,50,100,200$ and $400 \mu \mathrm{g} / \mathrm{mL}$ ) for 24 hours, the viability of cells was measured. As shown in Fig. 1, the groups treated at the concentration of $6.25-100 \mu \mathrm{g} / \mathrm{mL}$ showed almost no cytotoxicity. However, at the concentration of $200 \mu \mathrm{g} / \mathrm{mL}$, the viability of cells was about $80 \%$, and at $400 \mu \mathrm{g} / \mathrm{mL}$, lower than $70 \%$, which indicates the toxicity of the noni extract (Fig. 1). Based on the results, the concentration of $10-200 \mu \mathrm{g} / \mathrm{mL}$ was also additionally tested.

\section{Amount of NO produced by and iNOS expressed by noni extract}

The amount of NO produced by and iNOS expressed
(A)

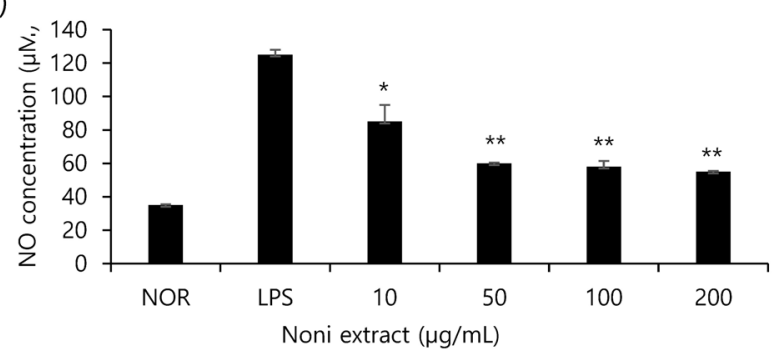

(B)

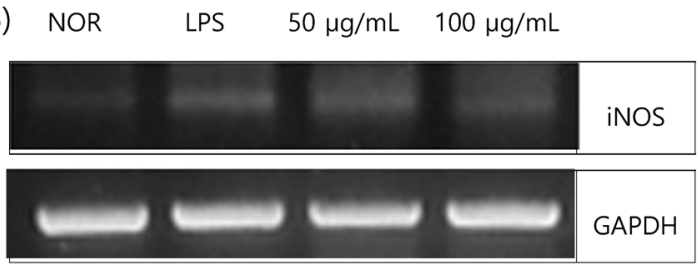

Fig. 2. Effect of noni extract on NO production and iNOS mRNA expression in RAW 264.7 cells stimulated by LPS. (A) Noni extract and LPS $(1 \mu \mathrm{g} / \mathrm{mL})$ at the following concentrations $(10,50,100$ and $200 \mu \mathrm{g} / \mathrm{mL})$ were stimulated for $24 \mathrm{~h}$ after treatment with RAW 264.7 cells. The Griess reaction was used to determine the $\mathrm{NO}$ concentration in the medium. The asterisks $\left(^{*}\right)$ indicate significant differences from the LPS group $\left({ }^{*} p<.05,{ }^{* *} p<.01\right)$. Error bars indicate standard deviation $(n=5)$. (B) Noni extract was stimulated for $24 \mathrm{~h}$ after treatment with RAW 264.7 cells $(1 \mu \mathrm{g} / \mathrm{mL})$ with the following concentrations (50 and $10 \mu \mathrm{g} / \mathrm{mL}$ ). Total RNA was isolated and quantified by GAPDH for quantitative comparison and expressed as a comparative graph, and the level of mRNA expression of iNOS was measured by RT-PCR.

by the noni extract in RAW 264.7 cells stimulated by LPS were measured. The produced amount of NO (Fig. 2A) and the expressed amount of iNOS mRNA (Fig. 2B) indicate that the inflammation-induced groups with LPS showed a sharp increase in the production of NO and the expression of iNOS mRNA, and that the groups treated 


\section{(A)}
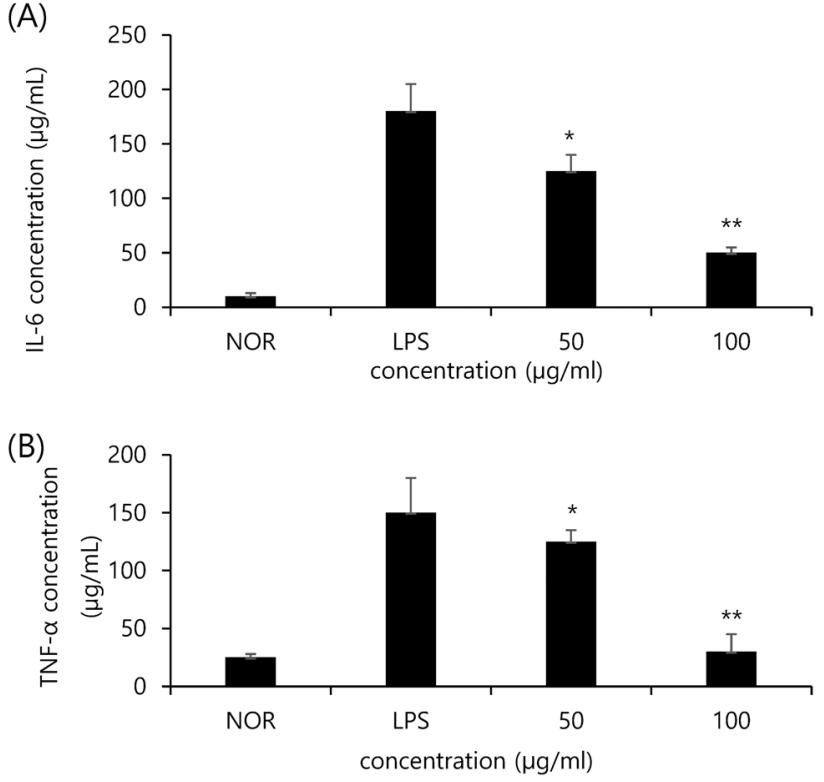

Fig. 3. The effect of noni extract on LPS-induced IL-6 (A) and TNF- $\alpha$ (B) release in RAW264.7 cells. The productions of TNF- $\alpha$ and IL-6, were assayed from culture supernatant of RAW264.7 cells stimulated by LPS $(1 \mu \mathrm{g} / \mathrm{mL})$ in the presence of testing samples (50 and $100 \mu \mathrm{g} / \mathrm{mL}$ ). The asterisks $\left(^{*}\right)$ indicate significant differences from the LPS group $\left({ }^{*} \not<.05,{ }^{* *} \not \alpha .01\right)$. Error bars indicate standard deviation $(n=5)$.

with the noni extract showed a decrease in the production of NO and the expression of iNOS mRNA in a concentration-dependent manner. As a result, the production of NO and iNOS inflammatory cytokines were inhibited by the noni extract, and these results demonstrate that the noni extract inhibits iNOS inflammatory cytokine genes, and thus the production of NO.

\section{Inhibitory effects of noni extract on TNF- $\alpha$ and IL -6}

IL-6 and TNF- $\alpha$ as inflammatory cytokines are involved in immunity functions and inflammatory reactions. In this study, the expression of cytokines IL-6 and TNF- $\alpha$ was found to be reduced by the noni extract in a concentration-dependent manner. As shown in Fig. 3A, IL-6 in the LPS group (LPS) increased due to LPS compared to the normal group (NOR). Whereas, the groups treated with $50 \mu \mathrm{g} / \mathrm{mL}$ and $100 \mu \mathrm{g} / \mathrm{mL}$ of the noni extract showed a lower expression of IL- 6 by $31 \%$ and $72 \%$ respectively compared to the Con. group. In the case of TNF- $\alpha$ (Fig. 3B), the expression of TNF- $\alpha$ in the Con. Group was 3.5

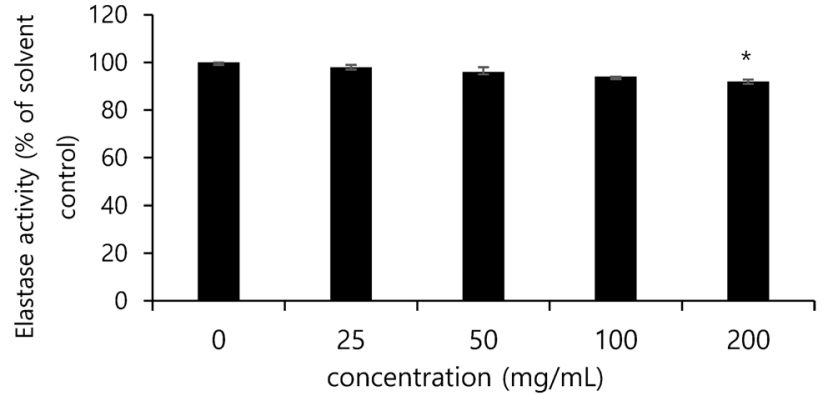

Fig. 4. Inhibitory effect of noni extract on elastase activity in human dermal fibroblasts after treatment. The data are expressed as \% of solvent control. The asterisk $\left(^{*}\right)$ indicates significant differences from the untreated group (* $p<.05)$. Error bars indicate standard deviation $(n=5)$.

times higher than the Nor. Group. In addition, the groups treated with $50 \mu \mathrm{g} / \mathrm{mL}$ and $100 \mu \mathrm{g} / \mathrm{mL}$ of the noni extract showed a lower expression of TNF- $\alpha$ by $17 \%$ and $80 \%$ respectively compared to the Con. group.

\section{Inhibitory effects on elastase activity}

The inhibitory effects of the Festuca ovina ethanol extract and each fractional extract against the activity of elastases were assessed, and the noni extract was found to significantly reduce the activity of elastases in a concentration-dependent manner. In particular, at the concentration of $100 \mu \mathrm{g} / \mathrm{mL}$, the activity of elastases was found to be inhibited by $7 \%$ than the solvent control group (Fig. 4).

\section{Measurement of synthesized Type I collagen}

Collagen is one of the major components of the extracellular matrix (ECM), and contributes to the elasticity of the skin. It also forms most of the organic matters of the skin and the body, and in particular a large amount of collagen exists in the dermis. Since collagen is closely related to wrinkles on the skin, lack of collagen generates wrinkles. Collagen is synthesized from pro-collagen, and has peptide sequences called propeptide at the amino terminus and carboxy terminus. For this reason, the biosynthesized amount of collagen can be estimated by measuring the amount of propeptide. In this study, changes in the synthesized amount of collagen by the treatment of the noni extract were measured using antibodies that perceive the 


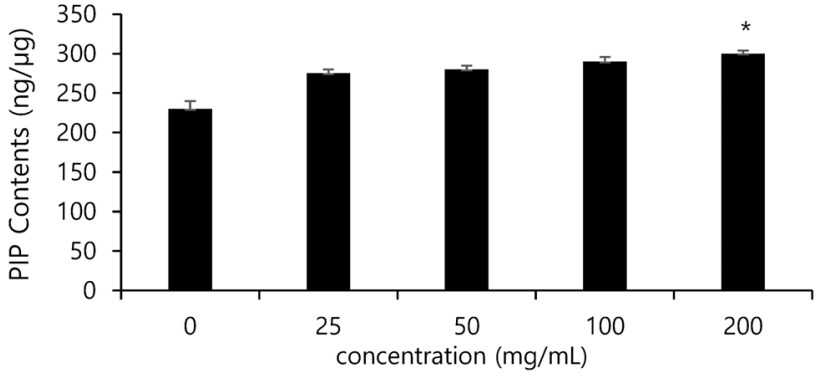

Fig. 5. Inhibitory effect of noni extract on PIP contents in human dermal fibroblasts after treatment. The data are expressed as \% of solvent control. The asterisk $\left(^{*}\right)$ indicates significant differences from the untreated group $\left({ }^{*} p<.05\right)$. Error bars indicate standard deviation $(n=5)$.

c-terminus of pro-collagen, and the amount of pro-collagen was found to increase in the groups treated with the noni extract $(25,50,100,200 \mu \mathrm{g} / \mathrm{mL})$ in a concentration-dependent manner. When the amount of pro-collagen in the non-treated group was set as $100 \%$, the group treated with the noni extract of $100 \mu \mathrm{g} / \mathrm{mL}$ showed an increase in the synthesized amount of collagen in cells by up to $20 \%$ compared to the solvent control group (Fig. 5).

\section{Inhibitory effects on MMP-1 activity}

Among MMPs, MMP-1 is a proteolytic enzyme that specifically acts on collagen, and the decomposition of collagen directly affects the decreasing elasticity of the skin and the generation of wrinkles. For this reason, inhibiting the activity of MMP-1 is expected to reduce the decomposition of collagen, and thus to maintain the elasticity of the skin and to inhibit the generation of wrinkles, and in this study the generated amount of MMP-1 was measured using a human Pro-MMP-1 Quantikine ELISA kit. The inhibitory effects of the noni extract at the concentration of $0,25,50,100$ and $200 \mu \mathrm{g} / \mathrm{mL}$ on the generation of MMP-1 were measured, and the noni extract was found to inhibit the generation of MMP-1 in concentration-dependent manner. In particular, the group treated with the noni extract of $100 \mu \mathrm{g} / \mathrm{mL}$ significantly reduced the activity of collagenases in cells by up to $25 \%$ compared to the solvent control group (Fig. 6).

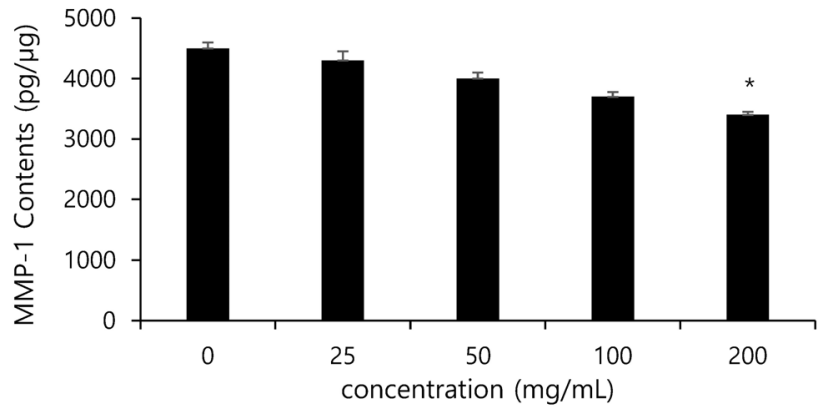

Fig. 6. Inhibitory effect of noni extract on MMP-1 contents in human dermal fibroblasts after treatment. The data are expressed as \% of solvent control. The asterisk $(*)$ indicates significant differences from the untreated group $\left({ }^{*} p<.05\right)$. Error bars indicate standard deviation $(n=5)$.

\section{Conclusion}

To examine the antioxidant, anti-inflammatory and anti-wrinkling effects of the noni extract, this study assessed its efficacy through an in-vitro test. For the antioxidant effect of the noni extract, its DPPH radical and ABTS radical scavenging activity was examined, and the antioxidant effect of the noni extract was found to be high, which verified the antioxidant efficacy of noni suggested by earlier studies. Based on the results, it can be concluded that noni is a natural substance that that has the antioxidant efficacy. Noni is taken in as food, and is expected to have no toxicity against the body. The viability of cells was analyzed, and it was verified that the noni extract did not show any cell death within the concentration of $100 \mu \mathrm{g} / \mathrm{mL}$. Based on the results, the expression of IL- 6 and TNF- $\alpha$ (inflammatory cytokines) and the production of NO were measured. At the concentration of 50 and $100 \mu \mathrm{g} / \mathrm{mL}$, the noni extract inhibited the expression of inflammatory factors in a concentration-dependent manner, which can be interpreted that the noni extract is effective in inhibiting or protecting the skin against aging caused by inflammation or wrinkles generated by aging. To verify this assumption, the anti-aging activity of the noni extract was measured. In the elastase activity inhibiting experiment, the noni extract $(25,50,100$ and $200 \mu \mathrm{g} / \mathrm{mL}$ ) was found to inhibit the activity by up to $7 \%$ at $100 \mu \mathrm{g} / \mathrm{mL}$ compared to the solvent control group. In the MMP-1 expression inhibiting experiment, the noni extract significantly inhibited the activity of collagenases 
in cells by up to $25 \%$ at $100 \mu \mathrm{g} / \mathrm{mL}$ in a concentrationdependent manner compared to the solvent control group. Lastly, the synthesized amount of Type I collagen was measured, and the noni extract was found to increase the produced amount of collagen in cells by up to $20 \%$ at $100 \mu \mathrm{g} / \mathrm{mL}$ in a concentration-dependent manner compared to the solvent control group. These results indicate that the noni extract, as a natural substance, can be utilized as a material for anti-aging and anti-wrinkling cosmetics, and that the noni extract is of sufficient value as a material for cosmetics that have antioxidant, anti-inflammatory and anti-wrinkling effects.

\section{References}

Ahn, B.K., R. Kim, D.B. Choi, and Y.S. Kim. 2011. Effect of Salicornia bigelovii extract on the activities of whitening and anti-wrinkle. Appl. Chem. Eng. 22(1):56-60.

Almeida-Souza, F., A.E.R. de Oliveira, A.L. Abreu-Silva, and K.S. Calabrese. 2018. In vitro activity of Morinda citrifolia Linn. fruit juice against the axenic amastigote form of Leishmania amazonensis and its hydrogen peroxide induction capacity in $\mathrm{BALB} / \mathrm{c}$ peritoneal macrophage. BMC Res. Notes. 11:492-496. https://doi.org/10.1186/s1 3104-018-3555-7

Blois, M.S. 1958. Antioxidant determinations by the use of a stable free radical. Nature 181:1199-1200. https://doi. org/10.1038/1811199a0

Choi, H.Y., B.C. Choi, and S.S. Sim. 2005. Antioxidant effects of noni (Morinda citrifolia) extracts treated with HCL and trypsin. YAHAK HOEJI [The Pharmaceutical Society of Korea] 49(5):410-415.

De La Cruz-Sánchez, N.G., A. Gómez-Rivera, P. Alvarez-Fitz, E. Ventura-Zapata, M.D. Pérez-García, M. Avilés-Flores, A.S. Gutiérrez-Román, and M. González-Cortazar. 2019. Antibacterial activity of Morinda citrifolia Linneo seeds against methicillin-resistant Staphylococcus spp. Microb. Pathog. 128:347-353. https://doi.org/10.1016/j.micpath. 2019.01.030

Hwang, H.J., K.O. Shin, and K.S. Han. 2019. A study on the function and role of Morinda citrifolia L. (Noni). Korean J. Food Nutr. 32(4):275-283. https://doi.org/10.9 799/ksfan.2019.32.4.275
Jung, H.N., H.J. Jeong, K.H. Shin, Y.S. Kim, J.H. Moon, and T.H. Lee. 2018. Protective effect of Thymus quinquecostatus extracts UVB-induced matrix metalloproteinase-1 via suppressing MAPKs phosphorylation in human keratinocyte. J. Appl. Biol. Chem. 61(4):417-421. https://doi.org/10.3839/jabc.2018.059

Kim, J.A., J.E. Lee, J.H. Kim, H.J. Lee, and N.J. Kang. 2019. Penta-1,2,3,4,6-O-galloyl- $\beta$-D-glucose inhibits UVB-induced photoaging by targeting PAK1 and JNK1. Antioxidants 8(11):561-579. https://doi.org/10.3390/anti ox8110561

Kim, J.M., S.W. Jeon, W.G. Lee, H.J. Nam, and Y.B. Kim. 2010. Study of preventing methods for skin aging and wrinkles. Korean J. Orient. Physiol. Pathol. 24(4):533-542.

Kim, M.J., T.K. Jung, H.C. Park, and K.S. Yoon. 2016. Skin volume augmentation and anti-wrinkle effects of Tribulus terrestris fruit extract. Korean Soc. Biotechnol. Bioeng. J. 31(3):178-185. https://doi.org/10.7841/ksbbj. 2016.31.3.178

Kim, S.G., H.D. Byun, S.C. Kim, K.W. Yang, J.H. Kim, and J.H. Han. 2015. Antioxidative and anti-inflammatory activities of carrot flower. Korean Soc. Biotechnol. Bioeng. J. 30(2):77-81. https://doi.org/10.7841/ksbbj.20 15.30.2.77

Kim, S.H. and H.J. Jang. 2016. Study on the bioactive characteristics of Morinda citrifolia as a cosmetic raw material. J. Soc. Cosmet. Sci. Korea 42(2):183-193. https://doi.org/10.15230/SCSK.2016.42.2.183

Kim, S.H., S.C. Jun, and Y.H. Hong. 2009. Anti-wrinkle and whitening effects of cosmetics using black garlic extract on skin care. J. Korean Soc. Cosmetol. 15(3): 1041-1050.

Lee, H.N., J.M. Lee, S.M. Hong, N.Y. Kim, S.J. Son, Y.J. Jeong, H.S. Lee, and J.S. Lee. 2018. Protective effects of ethanol extracts from selected food materials against UVB-induced damage in human skin fibroblast (Hs68) cells. J. Korean Soc. Food Sci. Nutr. 47(6):664-668. https://doi.org/10.3746/jkfn.2018.47.6.664

Lee, J.H., J.S. Moon, and T.B. Choe. 2013. The effects of cosmetics containing Schizandra chinesis extracts on the middle aged women's skin. J. Korean Soc. Cosmetol. 19(4):634-641.

Lee, J.N., S.W. Kim, Y.K. Yoo, G.T. Lee, and K.K. Lee. 2006. Anti-wrinkle effect of Morinda citrifolia (Noni) 
extracts. J. Soc. Cosmet. Sci. Korea. 32(4):227-231.

Lee, J.Y., E.K. Ahn, H.J. Ko, Y.R. Cho, W.C. Ko, Y.H. Jung, K.M. Choi, M.R. Choi, and J.S. Oh. 2014. Anti-melanogenic, anti-wrinkle, anti-inflammatory and anti-oxidant effects of Xylosma congesta leaf ethanol extract. J. Appl. Biol. Chem. 57(4):365-371. https://doi.org/10.3839/jabc.2014.058

Liu, T., N. Li, Y. Yan, Y. Liu, K. Xiong, Y. Liu, Q.M. Xia, H. Zhang, and Z.D. Liu. 2020. Recent advances in the anti-aging effects of phytoestrogens on collagen, water content, and oxidative stress. Phytother. Res. 34(3):435-447. https://doi.org/10.1002/ptr.6538

Liu, Y., F. Bai, T. Li, and H. Yan. 2018. An endophytic strain of genus Paenibacillus isolated from the fruits of Noni (Morinda citrifolia L.) has antagonistic activity against a Noni's pathogenic strain of genus Aspergillus. Microb. Pathog. 125:158-163. https://doi.org/10.1016/j. micpath.2018.09.018

Re, R., N. Pellegrini, A. Proteggente, A. Pannala, M. Yang, and C. Rice-Evans. 1999. Antioxidant activity applying an improved ABTS radical cation decolorization assay. Free Radic. Biol. Med. 26(9-10):1231-1237. https://doi. org/10.1016/S0891-5849(98)00315-3

Ye, Y.J., Y.S. Kim, and M.S. Kang. 2016. Effects of Citri Reticulatae Viride Pericarpium on 4-Hydroxynonenalinduced inflammation in PC12 cells. J. Korean Med. Obes. Res. 16(2):79-84. https://doi.org/10.15429/jkomo r.2016.16.2.79

Yong, W.S., Y.S. Kim, J.S. Park, Y.K. Jee, and K.Y. Lee. 2004. Characterization of nitric oxide (NO)-induced cell death in lung epithelial cells. Tuberc. Respir. Dis. 56(2):187-197. https://doi.org/10.4046/trd.2004.56.2.187

Youn, J.S., S.Y. Shin, Y. Wu, J.Y. Hwang, J.H. Cho, Y.G. Ha, J.K. Kim, M.J. Park, S. Lee, T.H. Kim, and T. Kim. 2012. Antioxidant and anti-wrinkling effects of Aruncus dioicus var. kamtschaticus extract. Korean J. Food Preserv. 19(3):393-399. 